\title{
NOVOS CRITERIOS PARA A ELABORACIÓN DUN DICIONARIO DE NEOLOXISMOS
}

\author{
Ana Belén Crespo Bastos / Xosé María Gómez Clemente
}

Observatorio de Neoloxía (Universidade de Vigo)

\section{O. INTRODUCIÓN}

Froito dos traballos do Observatorio de Neoloxía da Universidade de Vigo', en 2005 publicamos unha obra lexicográfica que denominamos Novas palabras galegas (López Fernández et alii 2005) e que reflectía a "vitalidade" (Cabré 2000, Gómez Clemente / Rodríguez Guerra 2003a) na creación de palabras que tiña a lingua galega. Nun anterior artigo fixemos unha pequena descrición desta obra (Gestido de la Torre / Gómez Clemente 2003). Recollíanse nela creacións léxicas que non estaban nos dicionarios galegos e que cumprían, polo tanto, un criterio de exclusión lexicográfica. Os criterios utilizados naquela obra deben ser revisados e ampliados e a información fornecida completada. Nesta contribución pretendemos:

(a) matizar os criterios de identificación de neoloxismos utilizados nos traballos do Observatorio de Neoloxía,

(b) describir unha serie de "marcas", algunhas derivadas do criterio de identificación e outras complementarias, que deberán ser empregadas en futuras edicións do devandito dicionarioº ${ }^{2}$ e

1. Este proxecto comezou en 1998. Nestes momentos faise unha avaliación dunha serie de fontes en Internet: www.vieiros.com; www.galicia-hoxe.com; www.canalciencia.com; www.anosaterra.com. En setembro de 2006, comezouse a analizar un blog, concretamente o chamado Brétemas de Manuel Bragado. Na base de datos, neste momento, están almacenados un total de 12.000 neoloxismos revisados.

2. Compróbense as marcas nos dicionarios de novas palabras do catalán (Observatori de Neologia 1998) e do italiano (Adamo / Della Valle 2003). O primeiro utiliza principalmente marcas lexicográficas (sobre o corpus de exclusión). O segundo inclúe tamén información morfolóxica e sintáctica sobre os procedementos de formación e identifica os formantes. 
(c) salientar a importancia que teñen as novas tecnoloxías para a elaboración de produtos lexicográficos, concretamente os extractores semiautomáticos de neoloxismos para a redacción de dicionarios de novas palabras.

\section{O CONCEPTO DE NEOLOXISMO E A SÚA IDENTIFICACIÓN}

As definicións de neoloxismo poden ser variadas, pero todas están centradas no feito de unha unidade ser considerada como "nova" nun sistema lingüístico determinado. Cabré (1993: 444) afirma que "o neoloxismo se pode definir como unha unidade léxica de formación recente, unha acepción nova dun termo xa existente ou, finalmente, un termo emprestado hai pouco dun sistema lingüístico estranxeiro"; Rey (1976: 4) defíneo como "une unité nouvelle, de nature lexicale, dans un code linguistique défini", e Boulanger (1989: 40) entende que "[o neoloxismo é o] resultado tanxible da operación de producción lingüística inédita [...], é dicir, a unidade nova capaz de encher cada baleiro detectado introducíndose no uso corrente ou socioprofesional". A novidade á que nos referiamos establécese basicamente con respecto a un criterio temporal (unha unidade é nova se apareceu recentemente nunha lingua), aínda que tamén pode referirse á ausencia desa palabra nun grupo de dicionarios ou á opinión sobre esa novidade que teñen os falantes.

Estas tres consideracións dan lugar a distintos criterios de identificación de neoloxismos:

\section{O criterio lexicográfico}

O criterio lexicográfico de identificación está baseado na comprobación sistemática da aparición da unidade léxica nunha serie de dicionarios: as que non se rexistran neles son consideradas como "neoloxismos lexicográficos". Este criterio, que á vez define o carácter do concepto neoloxismo, presenta certos problemas. Xa Corbeil (1971: 135-136) afirmaba que un dicionario nunca pode recoller todas as palabras dunha lingua ${ }^{3}$ e polo tanto o carácter neolóxico dunha unidade establecido con este criterio pode ser posto en dúbida 4 . Ademais, os lexicógrafos, cando elaboran as súas obras,

3. Este feito agrávase pola relativa limitación no número de entradas dos dicionarios utilizados no corpus de exclusión: VOLG (45.000), GDXL (95.000) e GDS XXI (80.000).

4. É significativo ver como os dicionarios, especialmente os académicos, son pouco permeables á introdución de palabras de uso frecuente. As gramáticas rexistran aínda con menor frecuencia novos formantes que poderían ser repertoriados nunha determinada lingua. Véxase Freixa / Solé (2003), que nos fornece datos moi significativos sobre a relación da neoloxía catalá cos dicionarios normativos nesa lingua. 
réxense por unha serie de normas que son máis ou menos permeables ás novas creacións léxicas, dependendo do tipo de dicionario que se elabore, da ideoloxía, da tradición, etc. Malia constatarmos estes feitos, o criterio de exclusión lexicográfica ten unha vantaxe, que é a da obxectividade na obtención dos datos e, dende logo, a facilidade de aplicación.

2. O criterio temporal, a frecuencia e o criterio psicolóxico-pragmático

Estes tres criterios deben ser considerados conxuntamente porque están estreitamente relacionados.

a) Criterio temporal e criterio da frecuencia

O criterio temporal baséase na constatación de que unha unidade léxica leva pouco tempo instalada nunha determinada lingua (velaquí a cerna do concepto de "neoloxismo"). Compróbase coas datas de aparición dunha palabra nun dicionario ou nun corpus textual para a atribución dunha teórica primeira ocorrencia nunha determinada lingua. Con respecto a isto temos que dicir que:

- Os dicionarios galegos non inclúen ningunha referencia a unha posible datación da palabra na lingua.

- As datas que se poden extraer dos corpora textuais galegos, CORGA e TILG, e da base de datos do Observatorio de Neoloxía deben ser utilizadas da seguinte maneira para establecer o criterio de novidade:

- Data da primeira ocorrencia. Neste sentido é máis útil o TILG por comezar os seus rexistros en 1612. O CORGA comeza a recoller os de 1975 e a base de datos do Observatorio comeza en 1998. Se consignamos esta primeira data, temos un dato obxectivo, pero hai que recoñecer que non é tarefa doada interpretar cando unha unidade léxica deixa de ser un neoloxismo, cantos anos teñen que pasar para que unha palabra xa non sexa considerada nova (estamos a falar de unidades léxicas non rexistradas en dicionarios). Quizais non haxa unha fronteira obxectiva, aínda que podemos entender que descentralizador, por exemplo, rexistrada en 1977 no CORGA xa non é un neoloxismo. Pero, unha palabra moi utilizada como represaliar, que se rexistra en 2001 tamén nesa base de datos, non nos dicionarios, é ou non é un neoloxismo 
despois de 5 anos? Quizais o único razoable sexa deixar a data da primeira ocorrencia para que sexa o usuario do dicionario de neoloxismos quen a interprete.

- Frecuencia e dispersión temporal. A análise destes parámetros leva a considerar que unha unidade, mesmo que se rexistre en data moi recuada, terá un maior carácter neolóxico (a) se ten unha baixa frecuencia, e (b) se, mesmo tendo unha frecuencia relativamente alta, a súa dispersión temporal é limitada. A baixa frecuencia dunha unidade contribúe en certa maneira a aumentar o seu carácter neolóxico porque a pouca difusión pode ser un indicador de que non tivo aceptación entre os falantes. Tamén poida que unha unidade tivese unha frecuencia alta durante un tempo pero despois desaparecese. Isto indica que pode ter un maior carácter neolóxico para os falantes que a volven recuperar pasado un tempo.

b) Criterio psicolóxico-pragmático

Falamos antes da dependencia que ten o criterio temporal da percepción sobre a novidade dunha palabra que teñen os usuarios da lingua. Alain Rey, cando fala do neoloxismo ${ }^{5}$, di que é imposible consideralo in abstracto como un elemento novo dentro dun sistema, independente do funcionamento concreto da lingua. Os neoloxismos defínense en relación cun modelo de comunicación determinado e, polo tanto, unha forma funcional limitada na súa función a un subsistema (dialecto, sociolecto) pode pasar a outro subsistema, no que será percibido como neoloxismo. É dicir, un neoloxismo tamén pode ser aquela unidade que ben por moda, por unha intervención institucional ou por outras causas pasa dun grupo de falantes a outro, ou dun rexistro de lingua a outro, independentemente da súa novidade obxectiva.

Para este autor, basear a neoloxía en criterios cronolóxicos ou lexicográficos presupón unha visión parcial dos fenómenos neolóxicos; daque-

5. Rey (1976: 17) defíneo así: "Le néologisme est une unité du lexique, mot, lexie ou syntagme, dont la forme signifiante ou la relation signifiant-signifié, caractérisée para un fonctionnement effectif dans un modèle de communication déterminé [novidade funcional], n'était pas réalisée au stade inmédiatement antérieur du code de la langue [sincronía]. Cette nouveauté, qui doit être appréciée par rapport à une définition précise et empirique du code [novidade pragmática], correspond en général à un sentiment spécifique chez les locuteurs [xuízo colectivo]. Selon le modèle de code choisi, on distinguira donc des néologismes en synchronie large et étroite, des néologismes pour la langue dans son ensemble ou pour un usage déterminé, des néologismes dans un contexte thématique spécialisé (technique et science) ou non spécialisé". 
la, fala do concepto de "impresión neolóxica", ou percepción da neoloxía por parte dos falantes, que debe estar baseada nun xuízo colectivo que supere os diferentes niveis de competencia que teñen os falantes. Este concepto de impresión neolóxica, difícil de cuantificar, é o que condiciona o criterio temporal, como antes dixemos ${ }^{6}$.

c) O concepto de "calidade neolóxica"

Á parte dos criterios citados, é necesario tamén falar da "calidade neolóxica" ( $\mathrm{CN}$ ) dunha unidade léxica, un concepto gradual que nos permite comprobar a novidade dunha palabra nun sistema lingüístico determinado, baseado principalmente no proceso polo cal se converteu en neoloxismo (Cabré et al. 2004). Neste traballo utilizamos a metodoloxía empregada polos autores do artigo citado para establecermos, cos nosos datos, os graos de calidade neolóxica que deberían logo ser reflectidos nunha obra lexicográfica dedicada ás novas palabras. Basicamente, a $\mathrm{CN}$ está baseada en criterios morfolóxicos, na análise dos compoñentes dunha palabra e na súa relación coas gramáticas e os dicionarios.

Presentamos os principais procesos de creación de novas palabras e a CN asociada a cada un deles.

a) Derivación por prefixación

- Se a base e mais o prefixo están repertoriados no corpus lexicográfico de exclusión e nas gramáticas: $\mathrm{CN} 0$.

- Se existe o prefixo e non a base: $+C N 1$.

- Se non se rexistra o prefixo e si a base: $+\mathrm{CN} 2$.

- Se non se rexistra nin o prefixo nin a base: $+\mathrm{CN} 3$.

- Se se altera algunha regra gramatical: $+C N 4$.

b) Derivación por sufixación

- A base e o sufixo están repertoriadas no corpus de exclusión e nas gramáticas: $\mathrm{CN} 0$.

- A base non está repertoriada e o sufixo si: $+C N 1$.

- A base está repertoriada e o sufixo non: $+C N 2$.

- Nin a base nin o sufixo están repertoriados: +CN 3.

6. Véxase tamén Gardin et al. (1974) e obsérvese a súa metodoloxía baseada en enquisas a un número determinado de falantes. 
c) Composición patrimonial ${ }^{7}$

- Se os dous elementos que forman o composto están repertoriados no corpus de exclusión: $\mathrm{CN} 0$.

- Se só aparece unha das bases que forman o composto: +CN 1 .

- Se non aparece ningún elemento repertoriado: +CN 2.

d) Composición culta ${ }^{8}$

- Os dous formantes están repertoriados: $\mathrm{CN} 0$.

- Un dos formantes non está repertoriado: +CN 1.

- Ningún dos formantes está repertoriado: +CN 2.

e) Composición híbrida9

- Se aparecen repertoriadas as bases e mais os formantes: $\mathrm{CN} 0$.

- Se non aparecen repertoriadas as bases: +CN 1 .

- Se non aparecen repertoriados os formantes: $+C \mathrm{CN} 2$.

- Se non aparecen nin as bases nin os formantes: $+\mathrm{CN} 3$.

f) Empréstitos ${ }^{10}$

- Se un empréstito está adaptado (A), a CN é menor porque se entende que leva máis tempo na lingua: $\mathrm{CN} 0$.

- Se un préstamo está sen adaptar (SA): +CN 1 .

- Se o empréstito non está repertoriado na lingua orixinal (LO): + CN 2 .

7. Na composición patrimonial integramos aquelas palabras que están formadas por unión de lexemas simples autónomos da lingua e que manteñen distinto grao de autonomía.

8. Entendemos por composición culta o procedemento polo cal se unen dous formantes de orixe grecolatina. Os exemplos rexistrados corresponden a neoloxía terminolóxica. Non hai unha relación exhaustiva de formantes cultos nos dicionarios e gramáticas galegas. Isto leva a que se consideren neoloxismos lexicográficos unidades que poida que estean recollidas en dicionarios especializados que non forman parte do noso corpus de exclusión e en obras dedicadas ao estudo teórico-práctico da terminoloxía.

9. Por composición híbrida entendemos a combinación de temas grecolatinos, ou truncacións de palabras modernas, cunha palabra moderna.

10. Véxanse os traballos de Rodríguez Río $(1998,2003)$ para unha completa relación dos procedementos de adaptación de empréstitos ao galego. 


\section{MARCAS NOS DICIONARIOS DE NEOLOXISMOS}

Entendemos que nunha obra lexicográfica que se poida definir como un repertorio de "novas palabras" deben incluírse unha serie de marcas que lle permitan ao usuario avaliar o grao de "neoloxicidade" das unidades léxicas extraídas cun criterio lexicográfico. Describiremos primeiro as marcas utilizadas no dicionario de Novas palabras galegas; a seguir, falaremos das novas marcas que serían necesarias en obras desta clase.

\subsection{O Dicionario de novas palabras (2005)}

O criterio utilizado para facer a escolla das entradas desta obra foi, como se dixo, o lexicográfico: incluíronse as palabras que non estaban no corpo de exclusión descrito. As marcas utilizadas foron as seguintes:

a) Lexicográficas

(1) O corpus de exclusión lexicográfica utilizado ata o ano 2000 foi o seguinte:

- VOLG (versión provisional 1989 // Corrixe 1.0-1.2).- É realmente o documento máis importante de todo o corpus de exclusión. Establece o léxico normativo e está realizado por unha institución que ten autoridade lingüística, derivada da Academia. Non serve para a análise da neoloxía semántica.

- DRAG (1997).- Non ten un número elevado de entradas (aproximadamente 25.000), pero ten a vantaxe de ser a única obra lexicográfica que ten un carácter normativo recoñecido e serve para analizar a neoloxía semántica.

(2) A partir do ano 2000 utilizouse o GDXL, que recolle un número moi elevado de entradas (95.000).

b) Textuais.- Fixéronse comprobacións adicionais en Internet para avaliar a difusión das entradas que aparecían na base de datos.

c) Temporais.- Indicáronse as datacións máis antigas rexistradas no CORGA e na nosa base de datos de neoloxismos.

Das 1.166 entradas que aparecían neste dicionario, 199 estaban presentes no GDXL, que se utilizou como parte do corpus de exclusión, aínda que tar- 
diamente. A marca GX00 apareceu en cada unha desas entradas para indicar que estaban nese dicionario. En 2005 incorporamos ao corpus de exclusión lexicográfica o GDS XXI. O emprego desta obra cando redactamos o dicionario de neoloxismos implicaría excluír 550 das súas entradas. Este dato mostra que a última obra citada se elaborou cun criterio aberto á aceptación de novas unidades léxicas que non tiveran entrada noutros dicionarios.

\subsection{Novas marcas nos dicionarios de neoloxismos}

Na redacción dun novo dicionario de neoloxismos cremos que se debería incluír unha serie de informacións complementarias que teñen que ver coa pequena revisión do noso concepto de neoloxismo que comentamos ao principio deste traballo.

Propoñemos a inclusión das seguintes marcas que dependen dos criterios descritos anteriormente ${ }^{11}$.

\section{(a) Marcas temporais}

En realidade, como comentamos, xa incluímos unha marca temporal no dicionario de 2005, pero agora propoñemos a súa comprobación sistemática en calquera fonte posible. Este criterio é o que máis se achega á definición que dan os autores que tratan sobre o concepto de neoloxismo. Enténdese, en principio, que unha unidade é neolóxica se aparece nunha época recente; non o é se é antiga. Consideramos que a única marca que se pode incluír é a da data da primeira documentación porque non podemos poñer un límite a partir do cal unha unidade deixa de ser neoloxismo (agás que entre nun dicionario).

Fixemos unha datación das unidades que estaban rexistradas no CORGA. Este corpus permite obter unha data aproximada da primeira ocorrencia da unidade que analizamos. Das 841 unidades rexistradas, 462 aparecen datadas neste corpus textual. A datación máis antiga é 1975 para a palabra centro-esquerda e a máis nova é para a palabra situacionismo de 2003. Entre estas dúas datas aparecen, entre outros, os seguintes exemplos:

[1975-1980] fraguismo, elitista, seguidista, castelán-falante, apartidista, atomización, reapropiación, minorizar, globalizador, departamental.

11. Para exemplificar esta información fixemos unha comprobación sobre 841 candidatos a neoloxismos do ano 2005, non rexistrados no corpus de exclusión lexicográfico, con 1334 ocorrencias. 
[1980-1990] on-line, modelización, privacidade, submundo, gay, profesionalización, sociopedagóxico, arbitrismo, impasse, corresponsabilidade.

[1990-2000] peonalización, xenocida, microrrede, aeroxerador, compós, e-mail, chat, recompilatorio, plurinacionalidade, risoterapia.

[2000-2003] alterglobalización, xogabilidade, jazzístico, pangaleguismo, eurobarómetro, punch, supervendas, router, teledermatoloxía, e-learning.

Como exemplos tirados da base de datos do Observatorio de Neoloxía podemos citar as de datación máis antiga:

[1997] deconstruccion, mercadeo, intramuros, medio ambiente.

(b) Marcas de frecuencia absoluta e dispersión temporal

(1) En principio, entendemos que se unha unidade é frecuente, o seu carácter neolóxico é menos evidente por repetida e, teoricamente, coñecida. Se a unidade é moi pouco frecuente, sucede á inversa:

\section{- Frecuencia alta:}

competencial 91, corresponsabilidade 64 , departamental 58, planeamento 54, vertebración 52, perigosidade 40, fraguismo 36 .

\section{- Frecuencia baixa:}

antiobreiro -a 2, apartidista 2, seguidista 5, potenciador -a 4, antinacionalista 17.

(2) Se unha unidade ten unha dispersión temporal ampla, o seu carácter neolóxico é menor. Se as ocorrencias están moi concentradas nuns determinados anos, pódese considerar que é máis "neolóxica":

- Ocorrencias dispersas:

planeamento 54: [1975-1984] 15; [1985-1994] 3; [1995-2004] 36.

- Ocorrencias concentradas:

departamental 58: [1975-1984] 1; [1985-1994] 3; [1995-2004] 54.

perigosidade 40: [1975-1984] 1; [1985-1994] 7; [1995-2004] 32.

plurinacional 51: [1975-1984] 8; [1985-1994] 5; [1995-2004] 38. 
Departamental aparece en 1977 pero rexistra 54 das súas ocorrencias a partir de 1995. O seu carácter neolóxico é evidente porque a meirande parte dos seus rexistros se dan nos últimos 10 anos. Perigosidade, da mesma maneira, aparece por primeira vez en 1977, pero concentra as súas ocorrencias a partir de 1995. No caso de plurinacional rexístranse 8 casos entre 1975 e 1979 e o seguinte rexistro xa é de 1993. Entre 1993 e 2004 rexístranse 43 das 51 ocorrencias.

(c) Marcas lingüísticas

Á parte das anteriores marcas, deberemos establecer que graos de novidade, ou calidade neolóxica $(\mathrm{CN})$, teñen as palabras segundo sexa o procedemento utilizado para formalas. A calidade neolóxica, como indicamos, establécese en relación coas gramáticas e dicionarios. Analizamos os seguintes casos:

- Derivación por prefixación:

- 0 [pref + base]. O prefixo e mais a base están repertoriados no corpus de exclusión e nas gramáticas. A súa CN é baixa. Así ocorre en multirreincidencia, deslocalización, precampaña, codecisión, teleformación, telecaza, dedocracia, mafiocracia.

- 1 [pref $+\varnothing]$. O prefixo está repertoriado; a base non. Maior grao de $\mathrm{CN}$ : antiviral, contraopa, insostibilidade, reubicación ${ }^{12}$.

- 2 [ $\varnothing$ + base]. O prefixo non está repertoriado; a base si. Grao de CN maior, xa que a aparición dun novo prefixo nunha lingua é un fenómeno neolóxico importante. Incluímos aquí os casos de neo-, que decidimos considerar prefixo pola súa ampla rendibilidade. Ex. neocolonia, neoconservador, neoliberal, neolicenciado.

- $3[\varnothing+\varnothing]$. Nin a base nin o prefixo están repertoriados. Grao de CN maior (non hai casos).

- 4 Alteración de regras gramaticais: [pref + substantivo = adxectivo]: [O alcalde nacionalista é cualificado de] antiobreiro, programa anticontaminación, mina antipersoa. Neste caso anti- non se comporta coma os outros prefixos xa que produce transcategorización. 
- Derivación por sufixación:

- 0 [base + suf]. A base e o sufixo están repertoriados. En principio, a CN da unidade é baixa porque, aínda que a impresión inicial sexa de novidade, os falantes poden identificar cada un dos compoñentes da nova palabra: anecdotario, conservacionista, comunicacional, condutual, conceptualidade, parabenizar.

- $1[\varnothing+$ suf]. A base non está repertoriada e o sufixo si. A CN é maior. Rexístranse casos con bases que son nomes propios, de marcas comerciais, préstamos e tamén de verbos, non rexistrados, derivados de substantivos. Ex.: mundialización, acebeiro, nominación, toyotismo, titulización, chateo, frontepopulista, blogueiro.

- $2[$ base $+\varnothing]$. A base está repertoriada e o sufixo non. Poden aparecer casos como a terminación -ing do inglés que nalgúns casos funciona como sufixo. Non rexistramos ocorrencias en 2005.

- $3[\varnothing+\varnothing]$. Nin a base nin o sufixo están repertoriados. Non se rexistran exemplos.

- Composición patrimonial:

- 0 [base + base]. As dúas bases están repertoriadas. A CN é baixa. Videochamada, videoconferencia, vídeoconsola, videocreación, escoitacontos, poema-imaxe, cd-libro.

- $1[\varnothing+$ base] ou [base $+\varnothing]$. Unha das bases non está repertoriada. Os exemplos que rexistramos teñen un elemento emprestado do inglés: blogmillo, blognovelado, netartista.

- $2[\varnothing+\varnothing]$. Non se rexistran exemplos.

- Composición culta ${ }^{13}$ :

- 0 [fprex + fsuf]. Rexístranse os dous formantes cultos: homofóbico.

13. Lémbrese o comentado antes sobre a presenza de neoloxismos terminolóxicos na nosa base que deberían ser tratados dunha forma diferente pola súa escasa aparición nos dicionarios. Ademais, as gramáticas tampouco recollen exhaustivamente os formantes cultos que funcionan na creación de unidades de valor especializado. 
- 1 [fprex $+\varnothing][\varnothing+$ fsuf]. Un dos formantes non está recollido no corpus de exclusión: dislipemia, cloroquina.

- $2[\varnothing+\varnothing]$. Non se rexistran exemplos.

- Composición híbrida:

- 0 [fprex + base] ou [base + fsuf]. Os dous elementos compositivos están repertoriados: aeroxerador, agrogandeiro, chupóptero, ecoeconomía, eurocidadán, euroconstitución, feminicidio, metrosexual, teleoperador.

- 1 [fpref $+\varnothing]$ ou $[\varnothing+$ fsuf]. Non está repertoriada a base, normalmente un préstamo adaptado ou sen adaptar: audioblog, ultrabiónico.

- $2[\varnothing+$ base $]$ ou [base $+\varnothing]$. Non se rexistra a forma prefixada ou sufixada no corpus: alterglobalización, cibercafé, cibersociedade, e-administración, e-ciencia, e-comercio, e-DNI .

- $3[\varnothing+\varnothing]$. Ningún elemento compositivo está repertoriado. Porén, o caso que rexistramos, altermundialización, produce unha impresión neolóxica baixa pola presenza de mundo, mundial.

- Préstamos:

- 0 (A). Como comentamos, os préstamos adaptados por importación ou calco, teñen, en principio, unha CN baixa: privacidade, párking, ránking, computerizar, compós.

- 1 (SA). Os préstamos sen adaptar teñen unha CN maior, aínda que moitos deles xa están na lingua cotiá de moitos falantes e, xa que logo, producen unha impresión neolóxica baixa: boom, hacker, driver.

- 2 (LO). Non se rexistran na lingua orixinal, onde funcionan como neoloxismos puros: godcasting, imode, blog, cromakey, book-crossing.

\section{CONCLUSIÓNS}

O criterio lexicográfico fornécenos dunha maneira sistemática candidatos a neoloxismos. A consideración dunha palabra como neoloxismo lexicográfico debe ser matizada coa aplicación doutros criterios. Os dicio- 
narios de neoloxismos deben presentarlle ao usuario a maior información posible sobre a cronoloxía, a frecuencia (a absoluta e a dispersión temporal) e os procedementos de formación das novas unidades, de maneira que poidan estes datos servirlle para formar o seu "xuízo" sobre a "calidade neolóxica" dunha palabra. En futuras ampliacións da nosa obra de 2005 introduciremos esta información e esperamos que sexa útil para a comprensión do concepto de neoloxismo. 